\title{
Remoción de Cromo (VI) por una Cepa de Paecilomyces sp Resistente a Cromato
}

\author{
Juan F. Cárdenas-González ${ }^{(1)}$, Víctor M. Martínez-Juárez ${ }^{(2)}$ e Ismael Acosta-Rodríguez ${ }^{(1)}$ \\ (1) Universidad Autónoma de San Luis Potosí, Facultad de Ciencias Químicas, Centro de \\ Investigación y de Estudios de Posgrado, Laboratorio de Micología Experimental. Av. Dr. Manuel \\ Nava No. 6, Zona Universitaria, 78320 San Luis Potosí, S.L.P. (e-mail: iacosta@uaslp.mx) \\ (2) Área Académica de Medicina Veterinaria y Zootecnia. Instituto de Ciencias Agropecuarias. \\ Universidad Autónoma del Estado de Hidalgo, México.
}

Recibido Sep. 15, 2010; Aceptado Nov. 12, 2010; Versión Final recibida Dic. 07, 2010

\section{Resumen}

Se analizó la capacidad de remoción de $\mathrm{Cr}(\mathrm{VI})$ de una cepa de Paecilomyces sp. Cuando el hongo se incubó en medio mínimo con glucosa y otras fuentes de carbono comerciales y de bajo costo, como azúcar moscabada y piloncillo ó glicerol, en presencia de $50 \mathrm{mg} / \mathrm{L}$ de $\mathrm{Cr}(\mathrm{VI})$, removió totalmente el $\mathrm{Cr}(\mathrm{VI})$. La reducción a $\mathrm{Cr}(\mathrm{III})$ ocurre en el medio de cultivo después de 7 días de incubación a $28^{\circ} \mathrm{C}, \mathrm{pH} 4.0$, y un inoculo de $38 \mathrm{mg}$. El hongo también redujo eficientemente la concentración de $\mathrm{Cr}(\mathrm{VI})$ a partir de tierra contaminada. Los resultados indican que la cepa de Paecilomyces sp tiene la capacidad de reducir $\mathrm{Cr}(\mathrm{VI})$ a $\mathrm{Cr}(\mathrm{III})$, y por lo tanto puede utilizarse para eliminar la contaminación por $\mathrm{Cr}(\mathrm{VI})$.

Palabras clave: remoción de cromo, biomasa fúngica, Paecilomyces sp, biorremediación

\section{Removal of Chromium (VI) in a Chromate-Resistant Strain of Paecilomyces sp}

\begin{abstract}
The ability to reduce chromium (VI) by a fungal strain of Paecilomyces sp was studied. When it was incubated in minimal medium with glucose and other inexpensive commercial carbon sources such as unrefined and brown sugar or glycerol, in the presence of $50 \mathrm{mg} / \mathrm{L}$ of $\mathrm{Cr}(\mathrm{VI})$, the strain caused complete removal of $\mathrm{Cr}(\mathrm{VI})$. The reduction to $\mathrm{Cr}$ (III) occurs in the growth medium after 7 days of incubation, at $28^{\circ} \mathrm{C}, \mathrm{pH} 4.0$, and inoculum of $38 \mathrm{mg}$. Also, the fungi efficiently reduced the concentration of $\mathrm{Cr}(\mathrm{VI})$ from contaminated soil wastes. The results indicate that the fungal strain of Paecilomyces sp has the capacity of reducing $\mathrm{Cr}(\mathrm{VI})$ to $\mathrm{Cr}(\mathrm{III})$, and therefore it could be useful for the removal of $\mathrm{Cr}(\mathrm{VI})$ pollution.
\end{abstract}

Keywords: chromium removal, fungal biomass, Paecilomyces sp, bioremediation 


\section{INTRODUCCIÓN}

La toxicidad del Cromo es una de las principales causas de contaminación ambiental, proveniente de los efluentes de tenerías. Este metal se utiliza en el curtido de cuero y pieles, así como en las aleaciones del acero, galvanoplastía, tinción de textiles y biocida en los sistemas de enfriamiento de aguas en plantas nucleares, lo cual resulta invariablemente en las descargas del metal al medio ambiente con sus consecuencias (Bay y Abraham, 2001). El $\mathrm{Cr}$ existe en 9 estados de valencia con un rango de $-2 \mathrm{a}+6$. De esos estados, únicamente el Cromo hexavalente [Cr(VI)] y el Cromo trivalente $[\mathrm{Cr}(\mathrm{III})]$ tienen importancia desde el punto de vista ambiental, pues son las formas de oxidación más estables en el medio ambiente (Smith, et. al., 2002). Ambas formas, se encuentran en diferentes fuentes de aguas y aguas residuales (Seng y Wang, 1994). El $\mathrm{Cr}(\mathrm{VI}) \mathrm{se}$ encuentra principalmente como cromato $\left(\mathrm{CrO}_{4}^{-2}\right)$ o dicromato $\left(\mathrm{Cr}_{2} \mathrm{O}_{7}^{-2}\right)$, dependiendo del pH de la solución (Seng y Wang, 1994). Ambos son muy solubles en agua y se absorben muy poco por el suelo y materia orgánica, por lo que son muy móviles en el suelo y agua (Smith, et. al., 2002), y representan un gran riesgo para la salud de animales y humanos, pues son muy tóxicos, mutagénicos carcinogénicos y/o teratogénicos (Marsh y Mclnerney, 2001).

En contraste, las formas de $\mathrm{Cr}(\mathrm{III})$, predominantemente hidróxidos, óxidos ó sulfatos, son mucho menos solubles en agua, menos móviles, 100 veces menos tóxicas y 1000 veces menos mutagénicas (Gutiérrez Corona, et. al., 2010). Las principales técnicas para recuperar o remover $\mathrm{Cr}(\mathrm{VI})$ de aguas residuales son: reducción química y precipitación, adsorción sobre carbón activado, intercambio iónico y ósmosis inversa. Actualmente, el proceso más empleado es la reducción de $\mathrm{Cr}(\mathrm{VI})$ a $\mathrm{Cr}(\mathrm{III})$ por la adición de un agente reductor, seguido por su precipitación como $\mathrm{Cr}(\mathrm{OH})_{3}$ por la adición de una solución básica, usualmente cal en un medio básico (Park, et. al., 2005). Sin embargo, esos métodos tienen ciertas desventajas, como el alto costo, baja eficiencia, generación de residuos tóxicos u otros que requieren disposición y que implican complejidad operacional (Sahin y Öztürk, 2005). La capacidad de algunos organismos para interactuar con diferentes formas de Cromo, los hace muy atractivos en el contexto de la biotecnología ambiental. En este sentido, actualmente hay muchos reportes del uso de biomasas microbianas para la remoción de $\mathrm{Cr}(\mathrm{VI})$ de aguas residuales industriales y/o contaminadas (Gutiérrez Corona, et. al., 2010).

Las propiedades de algunos microorganismos para tolerar y reducir $\mathrm{Cr}(\mathrm{VI})$ hacen posible su aplicación en procesos biotecnológicos enfocados a la destoxificación del mismo. Se ha descrito la resistencia a $\mathrm{Cr}(\mathrm{VI})$ en bacterias y hongos aislados de ambientes contaminados con el mismo. Las levaduras aisladas incluyen al género Candida y Rhodosporidium, aunque en éstas, el mecanismo general de resistencia a cromato está relacionado a la captura del ión, más bien que a una reducción química de las especies tóxicas (Baldi, et. al., 1990; Pepi y Baldi, 1992; Pat, et. al., 2004). Sin embargo, otras levaduras como Candida utilis (Muter, et. al., 2001 y Candida maltosa (Ramírez-Ramírez, et. al., 2004), mostraron capacidad para reducir el $\mathrm{Cr}(\mathrm{VI})$, y la acumulación del mismo en la biomasa. Reportes recientes han analizado la captura y acumulación de $\mathrm{Cr}(\mathrm{VI})$ y $\mathrm{Cr}$ (III) por diferentes hongos filamentosos (Acevedo-Aguilar, et. al., 2008; Fukuda, et. al., 2008; Srivastava y Thakur, 2006; Morales-Barrera y Cristiani-Urbina, 2008). El presente trabajo reporta la remoción y/o reducción de $\mathrm{Cr}(\mathrm{VI})$ por una cepa fúngica de Paecilomyces sp que presenta alta resistencia al mismo metal.

\section{METODOLOGÍA}

\section{Microorganismo}

Se trabajo con una cepa de Paecilomyces sp resistente a $\operatorname{Cr}(\mathrm{VI})$ y aislada a partir de aire contaminado de una zona aledaña a la Facultad de Ciencias Químicas, de la UASLP San Luis Potosí, S.L.P., México (Cárdenas-González y Acosta Rodríguez, 2011), la cual se mantuvo de manera rutinaria en Medio Mínimo de Lee modificado (LMM) conteniendo 1.0\% de agar, 0.25\% de $\mathrm{KH}_{2} \mathrm{PO}_{4}, 0.20 \%$ de $\mathrm{MgSO}_{4}, 0.50 \%$ de $\left(\mathrm{NH}_{4}\right)_{2} \mathrm{SO}_{4}, 0.50 \%$ de $\mathrm{NaCl}$ y $0.25 \%$ de glucosa como fuente de carbono, y complementado con $500 \mathrm{mg} / \mathrm{L}$ de $\mathrm{K}_{2} \mathrm{Cr}_{2} \mathrm{O}_{7}$. 


\section{Estudios de remoción}

Para los experimentos relacionados con la remoción de $\mathrm{Cr}(\mathrm{VI})$, se inocularon $5 \times 10^{5}$ esporas $/ \mathrm{mL}$, a $100 \mathrm{~mL}$ de $\mathrm{LMM}$, complementados con $50 \mathrm{mg} / \mathrm{L}$ de $\mathrm{Cr}(\mathrm{VI})\left(\mathrm{K}_{2} \mathrm{Cr}_{2} \mathrm{O}_{7}\right)$, y se incubaron a $28^{\circ} \mathrm{C}$ por $48 \mathrm{~h}$. Después, en condiciones estériles las células se separaron por centrifugación a 2,000 rpm a $4^{\circ} \mathrm{C}$ durante $10 \mathrm{~min}$, se lavaron 3 veces con agua tridesionizada para eliminar el medio de cultivo y restos celulares, se resuspendieron en $3 \mathrm{~mL}$ de agua tridesionizada estéril por agitación durante 30 s. en Vortex, y se transfirieron a $100 \mathrm{~mL}$ de LMM fresco complementado con $50 \mathrm{mg} / \mathrm{L}$ de $\mathrm{Cr}(\mathrm{VI})$. A diferentes tiempos, se tomaron alícuotas de $1 \mathrm{~mL}$, las cuales se centrifugaron a 5,000 rpm por $10 \mathrm{~min}$; el sobrenadante se utilizó para determinar la concentración de $\mathrm{Cr}(\mathrm{VI})$ y $\mathrm{Cr}$ (III) por los métodos espectrofotométricos de la Difenilcarbazida y Chromazurol $\mathrm{S}$, respectivamente (Greenberg et. al., 1992; Pantaler y Pulyaeva, 1985) y el $\mathrm{Cr}$ total por Espectrofotometría de Absorción Atómica (Greenberg et. al., 1992). Todos los experimentos se realizaron mínimo 3 veces y por triplicado.

\section{RESULTADOS Y DISCUSIÓN}

La Figura 1 muestra el efecto de diferentes pH's (4.0, 5.3, 7.0, mantenidos con regulador de citrato-fosfato $100 \mathrm{mMol} / \mathrm{L})$ sobre la remoción de $\mathrm{Cr}(\mathrm{VI})$. La velocidad y porcentaje de remoción del metal, aumentan a medida que disminuye el pH de 7.0 a 4.0. La máxima remoción se observó a pH de 4.0 (96\% a los 7 días de incubación, a $28^{\circ} \mathrm{C}$ y $\left.100 \mathrm{rpm}\right)$. Sandana Mala et. al., (2006), reportaron una remoción máxima a una concentración de $100 \mathrm{mg} / \mathrm{L}$ de $\mathrm{Cr}(\mathrm{VI})$, usando Aspergillus niger MTCC 2594, con un pH óptimo de 5.0, Rodríguez et. al., (2008), a pH 3.0-5.0 para $\mathrm{Pb}^{+2,} \mathrm{Cd}^{+2}$ and $\mathrm{Cr}^{+3}$ con la levadura Saccharomyces cerevisiae, y Fukuda et. al., (2008), a pH 3.0 también para $\mathrm{Cr}(\mathrm{VI})$ con el hongo Penicillium sp. En contraste a nuestras observaciones, Prasenjit y Sumathi (2005), reportaron una mayor remoción de $\mathrm{Cr}(\mathrm{VI})$ a $\mathrm{pH} 7.0$ con el hongo Aspergillus foetidus, Al-Asheh y Duvnjak (1995), también demostraron un efecto positivo al aumentar el pH en un rango de 4.0 a 7.0 sobre la remoción de $\mathrm{Cr}(\mathrm{III})$ con Aspergillus carbonarius. Una baja en el pH causa la protonación de la superficie del adsorbente, lo que induce una fuerte atracción por los iones $\mathrm{Cr}(\mathrm{VI})$ de la solución cargados negativamente, por lo que la bioadsorción aumenta al aumentar la acidez de la solución. Pero cuando el pH aumenta, se incrementa la concentración de iones $\mathrm{OH}$-, induciendo cambios en la superficie del adsorbente, impidiendo la bioadsorción de los iones $\mathrm{Cr}(\mathrm{VI})$ cargados negativamente, lo cual disminuye la adsorción del metal a valores de $\mathrm{pH}$ altos (Gadd, 1981).

Por otro lado, se analizó el efecto de la concentración de la biomasa celular sobre la capacidad de remoción de $\mathrm{Cr}(\mathrm{VI})$ en solución (Figura 2). A las concentraciones analizadas (38, 76, y $114 \mathrm{mg}$ de peso seco), la capacidad de remoción fue similar (99.17\%, 97.95\%, y 97.25\%, respectivamente). En contraste a nuestras observaciones, la mayoría de los reportes en la literatura indican que a mayor cantidad de biomasa aumenta el porcentaje de remoción (Srivastava y Thakur, 2006; Morales-Barrera y Cristiani-Urbina, 2008; Rodríguez et. al., 2008), pues a mayor cantidad de inoculo, hay más sitios de unión para acomplejar el metal (por ejemplo, los iones $\mathrm{HCrO}_{4}^{-} \mathrm{y} \mathrm{Cr}_{2} \mathrm{O}_{7}^{-2}$ ) (Cervantes et. al., 2001). Cómo se observa en la Figura 3, cuando se incrementa la concentración inicial de $\mathrm{Cr}(\mathrm{VI})$ de 50 a $200 \mathrm{mg} / \mathrm{L}$, disminuye el porcentaje de remoción del metal, lo cual puede deberse al incremento en el número de iones que compiten por los grupos funcionales disponibles en la superficie de la biomasa fúngica. Nuestras observaciones son parecidas a la mayoría de los reportes de la literatura (Srivastava y Thakur, 2006; Morales-Barrera y Cristiani-Urbina, 2008; Gutiérrez Corona et. al., 2010).

Las Figuras $4 \mathrm{a}$ y $4 \mathrm{~b}$, muestran que la disminución en los niveles de $\mathrm{Cr}(\mathrm{VI})$ por el hongo en el medio de cultivo, ocurren exclusivamente en presencia de una fuente de carbono fermentable (glucosa sacarosa, fructosa) u oxidable (glicerol). En presencia de glucosa, otras fuentes de carbono comerciales y económicas como azúcar moscabada y piloncillo ó glicerol, la remoción de $\mathrm{Cr}(\mathrm{VI})$ es muy similar a los 7 días de incubación (99.17\%, 100\%, 94.28\% y 99\%, respectivamente), mientras que las otras fuentes de carbono analizadas fueron menos efectivas. Por otro lado, la incubación de la biomasa en el medio de crecimiento sin fuentes de carbono, no produce cambios significativos en la concentración inicial de $\mathrm{Cr}(\mathrm{VI})$, lo cual indica que se requiere una fuente de 
carbono en el medio de cultivo para proporcionar el poder reductor necesario para disminuir la concentración de $\mathrm{Cr}(\mathrm{VI})$ en el medio de cultivo. Nuestras observaciones son parecidas a las reportadas por Acevedo-Aguilar, et. al., (2008) y Prasenjit y Sumathi (2005) y Coreño-Alonso et. al., (2009) con glucosa como fuente de carbono, pero son diferentes a las observaciones de Srivasta y Thakur (2006), con Aspergillus sp, quienes observaron que el acetato de sodio fue la fuente de carbono que indujo una mayor remoción de $\mathrm{Cr}(\mathrm{VI})$.
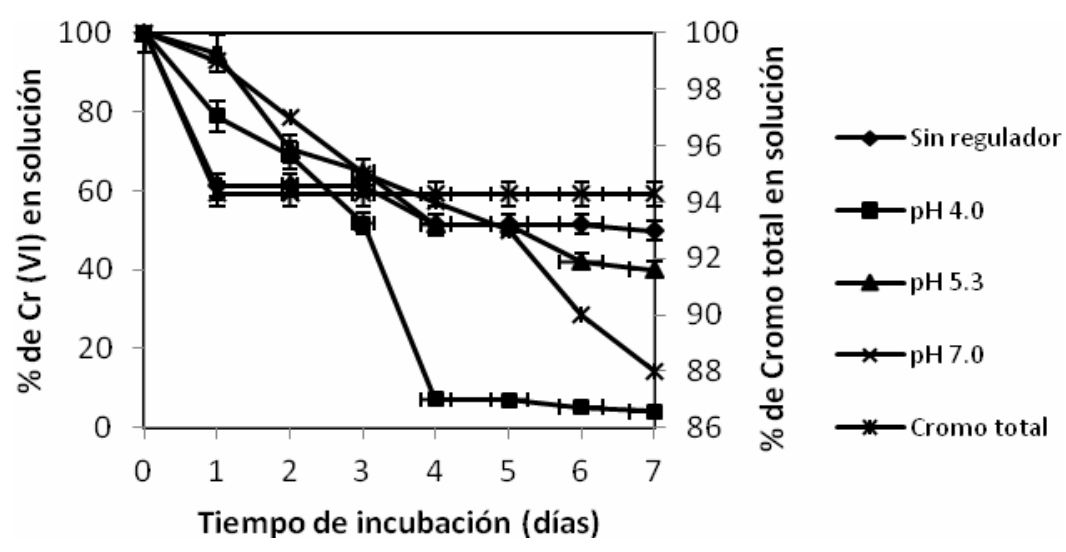

Fig. 1: Efecto del pH inicial sobre la remoción de $\mathrm{Cr}(\mathrm{VI})(50 \mathrm{mg} / \mathrm{L})$ in vivo por Paecilomyces sp. $100 \mathrm{rpm}, 28^{\circ} \mathrm{C}$.
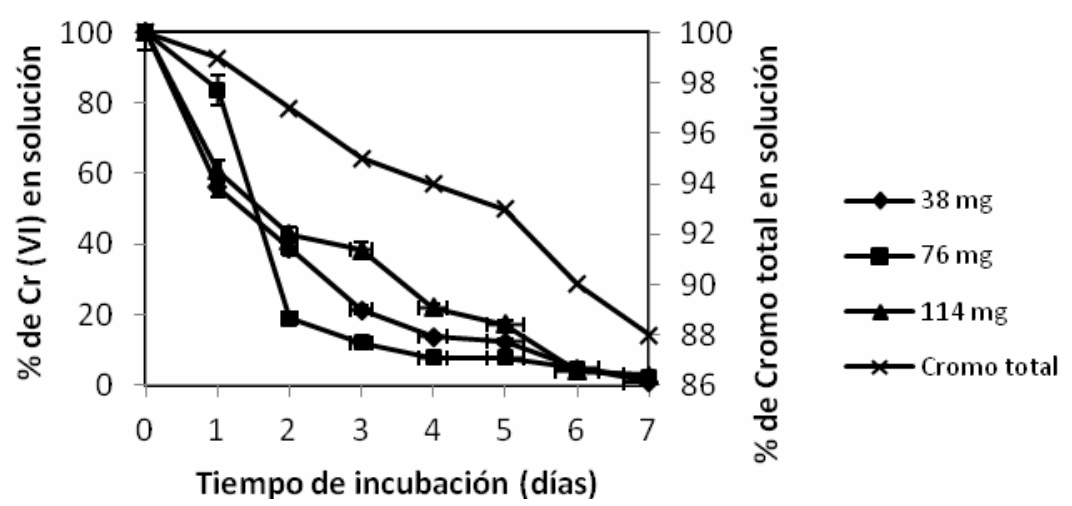

Fig. 2: Efecto de la concentración del preinoculo sobre la remoción de $\mathrm{Cr}(\mathrm{VI})(50 \mathrm{mg} / \mathrm{L})$ in vivo por Paecilomyces sp. $\mathrm{pH} 4.0,28^{\circ} \mathrm{C}, 100 \mathrm{rpm}$.

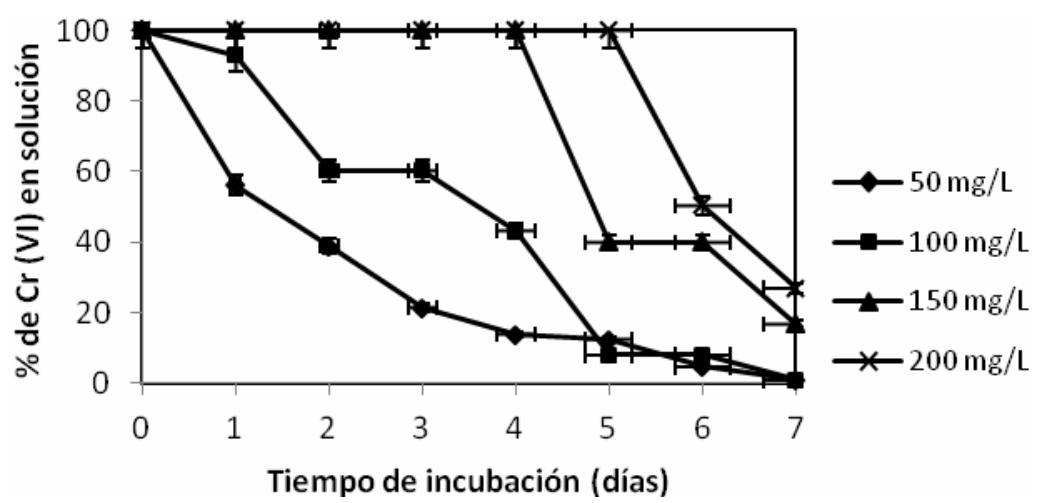

Fig. 3: Efecto de la concentración de $\mathrm{Cr}(\mathrm{VI})$ sobre la remoción del mismo, in vivo por Paecilomyces sp. $\mathrm{pH} 4.0,28^{\circ} \mathrm{C}, 100 \mathrm{rpm}$. 
Debido a que la movilidad y toxicidad del $\mathrm{Cr}$ depende de su estado de oxidación, las reacciones redox que lo involucran son importantes para su destino en el ambiente y riesgo para la salud, se ha sugerido que su reducción en ambientes contaminados resulta de una interacción compleja de procesos bióticos y abióticos (Gutiérrez Corona et. al., 2010). Además, el $\mathrm{Cr}(\mathrm{VI})$ puede ser reducido a $\mathrm{Cr}(\mathrm{III})$ en el suelo por reacciones redox con especies inorgánicas acuosas, transferencia de electrones en superficies minerales, reacción con substancias orgánicas no húmicas, (carbohidratos y proteínas), ó reducción por substancias húmicas del suelo (Palmer y Wittbrodt, 1991). También, la actividad microbiana puede contribuir a su reducción en estos ambientes contaminados, a través de la liberación del ión ferroso, sulfuros o intermediarios orgánicos reactivos (Buerge y Hug, 1998).
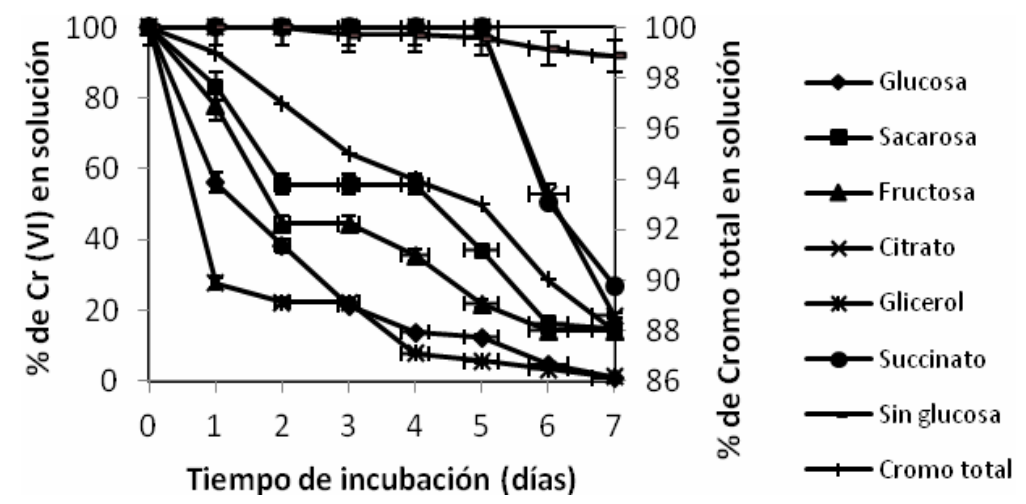

Fig. 4a: Efecto de diferentes fuentes de carbono sobre la remoción de $50 \mathrm{mg} / \mathrm{L}$ de $\mathrm{Cr}(\mathrm{VI})$ in vivo, por Paecilomyces sp. $\mathrm{pH} 4.0,28^{\circ} \mathrm{C}, 100 \mathrm{rpm}$.
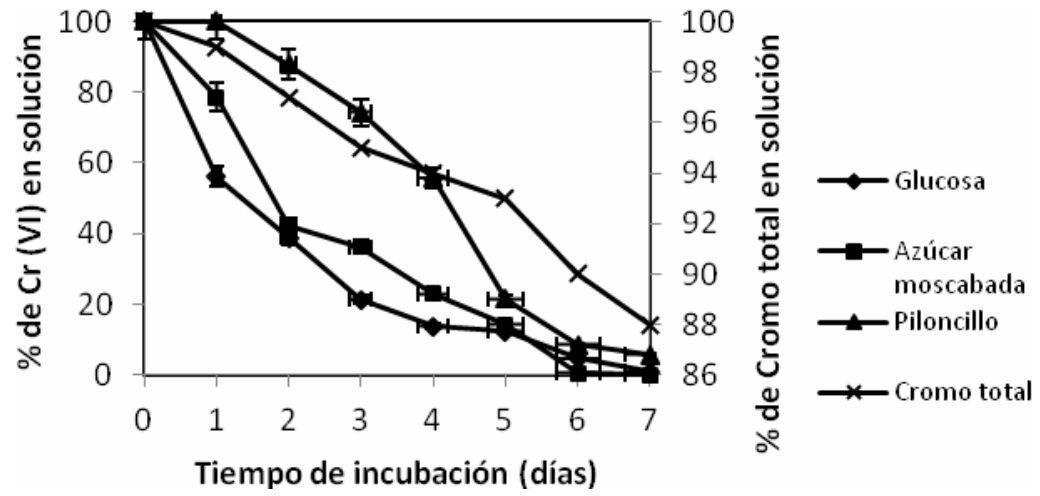

Fig. 4b: Efecto de diferentes fuentes de carbono comerciales + sal común sobre la remoción de $50 \mathrm{mg} / \mathrm{L}$ de $\mathrm{Cr}(\mathrm{VI})$ in vivo por Paecilomyces sp. $\mathrm{pH}$ $4.0,28^{\circ} \mathrm{C}, 100 \mathrm{rpm}$.

Se analizó la capacidad del hongo para disminuir $50 \mathrm{mg} / \mathrm{L}$ de $\mathrm{Cr}(\mathrm{VI})$ y la producción de $\mathrm{Cr}(\mathrm{III})$ en el medio de cultivo. En la Figura 5 se observa que después de 7 días de incubación, Paecilomyces sp disminuye la concentración del metal, hasta niveles indetectables, con la producción concomitante de $\mathrm{Cr}(\mathrm{III})$, sin cambios significativos en los niveles de $\mathrm{Cr}$ total en el medio de cultivo sin inoculo. Lo anterior indica que el hongo es capaz de reducir $\mathrm{Cr}(\mathrm{VI})$ a $\mathrm{Cr}(\mathrm{III})$ en el medio suplementado con cromato. Se han descrito dos mecanismos por los cuales el cromato puede ser reducido a un estado de oxidación menos tóxico, uno que involucra reacciones enzimáticas. Nosotros no sabemos si la cepa fúngica analizada expresa enzimas que reducen $\mathrm{Cr}(\mathrm{VI})$, por lo que se requieren más estudios para entender los efectos de los iones involucrados en dicha actividad reductora, aunque la capacidad de reducción se ha reportado en la literatura (Gutiérrez Corona et. al., 2010). El segundo mecanismo por el cual se puede reducir la concentración de cromato es la bioadsorción. Al respecto, $1.0 \mathrm{~g}$ de biomasa fúngica es capaz de remover 1000 $\mathrm{mg} / \mathrm{L}$ de $\mathrm{Cr}(\mathrm{VI})$ a $60^{\circ} \mathrm{C}$, a las $3 \mathrm{~h}$ de incubación (Cárdenas-González y Acosta-Rodríguez, 2011). 
La pared celular fúngica tiene diferentes grupos funcionales que pueden formar complejos de coordinación con los metales, lo que puede facilitar la remoción de los mismos en solución. Además, nuestras observaciones son similares a la mayoría de reportes de la literatura (MoralesBarrera y Cristiani-Urbina, 2008; Rodríguez et. al., 2008).

También, se realizó un estudio de biorremediación, en el cual se inocularon $5 \times 10^{5}$ esporas $/ \mathrm{mL}$, a $100 \mathrm{~mL}$ de LMM (pH 4.0) incubando a $28^{\circ} \mathrm{C}$ por $48 \mathrm{~h}$ a $100 \mathrm{rpm}$; después se añadieron $20 \mathrm{~g}$ de tierra no estéril, contaminada con $50 \mathrm{mg} \mathrm{Cr}(\mathrm{VI}) / \mathrm{g}$ de tierra, obtenida de una tina de lavado de una cromadora de Celaya, Gto, México, a diferentes tiempos se tomaron alícuotas de $5 \mathrm{~mL}$, y se centrifugaron a 5,000 rpm por $10 \mathrm{~min}$; el sobrenadante se utilizó para determinar la concentración de $\mathrm{Cr}(\mathrm{VI})$, observando que después de 8 días de incubación, disminuye totalmente el metal en solución (Figura 6), sin cambios significativos en el contenido de $\mathrm{Cr}$ total, y en un experimento realizado en ausencia de la cepa fúngica, la concentración de $\mathrm{Cr}(\mathrm{VI})$ de la muestra de suelo disminuye aproximadamente un $18 \%$ (datos no mostrados), lo cual puede ser causado por la microflora nativa y/o a componentes reductores presentes en el suelo contaminado. La capacidad de remoción de $\mathrm{Cr}(\mathrm{VI})$ por el hongo, es igual o mejor a las de otras cepas reportadas, como Candida maltosa RR1 (Ramírez-Ramírez et., al.; 2004). Tal vez, esta cepa fue superior a las otras reportadas, debido a su capacidad de reducir eficientemente $\mathrm{Cr}(\mathrm{VI})$ bajo condiciones acídicas. La mayoría de estudios de reducción de $\mathrm{Cr}(\mathrm{VI})$ por microorganismos han sido realizados a pH neutro (Ramírez-Ramírez, et., al. 2004; Acevedo-Aguilar, et., al. 2008). También, Aspergillus niger tiene la capacidad de reducir y adsorber $\mathrm{Cr}(\mathrm{VI})$ (Srivastava, and Thakur 2006), pues el hongo remueve $8.9 \mathrm{mg}$ de cromo/g de peso seco de micelio a los 7 días de incubación. Los reportes sobre aplicaciones de microorganismos para estudios de biorremediación de suelos contaminados con cromato son escasos, como el empleo de bacterias no identificadas, nativas del sitio contaminado, encontrando que la reducción máxima de $\mathrm{Cr}(\mathrm{VI})$ ocurrió con el empleo de $15 \mathrm{mg}$ de biomasa bacteriana/g de suelo (peso húmedo), con $50 \mathrm{mg}$ de melasas/g de suelo como fuente de carbono; reduciendo completamente $5.6 \mathrm{mg} \mathrm{Cr}(\mathrm{VI}) / \mathrm{g}$ de suelo en 20 días (Jeyasingh y Philip, 2004). En otro estudio se utilizaron bacterias reductoras de $\mathrm{Cr}(\mathrm{VI})$ no identificadas, nativas de un sitio contaminado, encontrando que la reducción de $50 \mathrm{mg} / \mathrm{L}$ de $\mathrm{Cr}(\mathrm{VI})$ por las bacterias fue de alrededor de un $80 \%$, con $10 \mathrm{~g} / \mathrm{L}$ de peptona como fuente de electrones y un tiempo de retención hidráulica de $8 \mathrm{~h}$. El $\mathrm{Cr}(\mathrm{III})$ producido fue removido utilizando una columna con el hongo Ganoderma lucidum, siendo la capacidad específica de adsorción de $\mathrm{Cr}$ (III) por el hongo en la columna de 576 mg/g (Krishna y Philip, 2005).

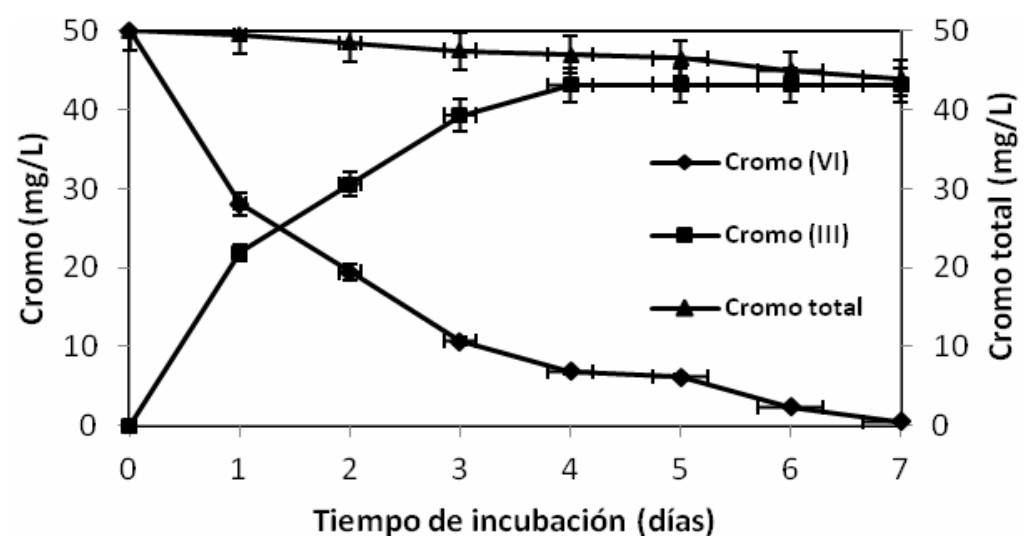

Fig. 5: Reducción de $\mathrm{Cr}(\mathrm{VI})$ a $\mathrm{Cr}(\mathrm{III})$ en Medio Mínimo de Lee conteniendo $50 \mathrm{mg} / \mathrm{L} \mathrm{Cr}(\mathrm{VI}), \mathrm{pH} 4.0,100 \mathrm{rpm}, 28^{\circ} \mathrm{C}$. 


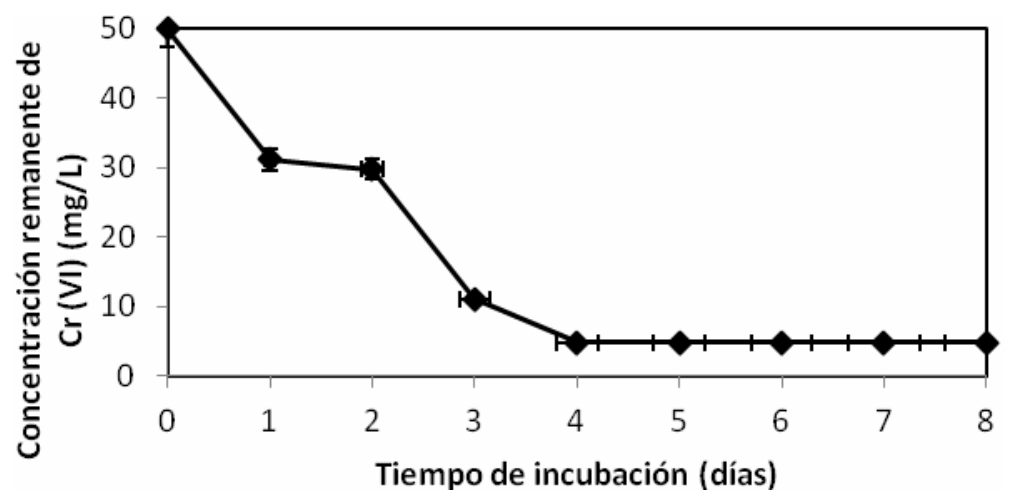

Fig. 6: Biorremediación de $\mathrm{Cr}(\mathrm{VI})$ a partir de tierra contaminada (50 mg $\mathrm{Cr}(\mathrm{VI}) / \mathrm{g}$ tierra) por la biomasa de Paecilomyces sp. $28^{\circ} \mathrm{C}, 100 \mathrm{rpm}$.

\section{CONCLUSIONES}

La cepa fúngica de Paecilomyces sp, eliminó completamente $50 \mathrm{mg} / \mathrm{L}$ de $\mathrm{Cr}(\mathrm{VI})$ en el medio de cultivo a los 7 días de incubación, a $28^{\circ} \mathrm{C}, \mathrm{pH}, 4.0,100 \mathrm{rpm}$ y un inoculo de $38 \mathrm{mg}$ de peso seco. Estos resultados sugieren la potencial aplicación de éste hongo para la biorremediación de sitios contaminados con $\mathrm{Cr}(\mathrm{Vl})$.

\section{REFERENCIAS}

Acevedo-Aguilar, F., A. y otros 7 autores, Analytical speciation of chromium in in-vitro cultures of chromate-resistant filamentous fungi, Analytical and Bioanalytical Chemistry: 392, 269-276 (2008).

Al-Asheh, S. y Z. Duvnjak, Adsorption of copper and chromium by Aspergillus carbonarius, Biotechnology Progress: 11, 638-642, (1995).

Bai, R.S. y T.E. Abraham, Biosorption of chromium (VI) from aqueous solution by Rhizopus nigricans, Bioresource Technology: 79, 73-81 (2001).

Baldi, F., A.M. Vaughan, and G.J. Olson, Chromium (VI)-resistant yeast isolated from a sewage treatment plant receiving tannery waste, Applied and Environmental Microbiology: 56, 913-918 (1990).

Buerge, I.J. y Hug, S.J. Influence of organic ligands on chromium(VI) reduction by iron(II). Environmental Science and Technology: 32 (14), 2092- 2099 (1998).

Cárdenas-González, J.F. e I. Acosta-Rodríguez, Remoción de cromo hexavalente por el hongo Paecilomyces sp. aislado del medio ambiente. Información Tecnológica: 22, (1) (2011). En Prensa.

Coreño-Alonso, A., y otros 7 autores, $\mathrm{Cr}(\mathrm{VI})$ reduction by an Aspergillus tubingensis strain: rol of carboxylic acids and implications for natural attenuation and biotreatment of $\mathrm{Cr}(\mathrm{VI})$ contamination. Chemosphere: 76 (1), 43-47 (2009).

Fukuda, T. y otros 4 autores, $\mathrm{Cr}(\mathrm{VI})$ reduction from contaminated soils by Aspergillus sp. N2 and Penicillium sp. N3 isolated from chromium deposits, Journal of General Applied Microbiology: 54, 29

Gadd, G.M. Accumulation of metals by microorganisms and algae. In: Rhem H.J., Reed G (eds) Biotechnology: a comprehensive treatise. $\mathrm{VCH}$, Weinheim, Germany, Vol 6B, pp. 401-433. 5-303 (2008).

Greenberg, A.E., L.S. Clesceri and A.D. Eaton, Standard methods for the examination of water and wastewater, $18^{\mathrm{a}}$ ed. American Public Health Association, Washington, D.C. 3, pp. 58-3.60, 187-190, (1992). 
Gutiérrez Corona, J.F. y otros ocho autores, Mecanismos de interacción con cromo y aplicaciones biotecnológicas en hongos, Revista Latinoamericana de Biotecnología Ambiental y algal: 1(1), 47-63 (2010).

Jeyasingh, J., y Philip, L. Bioremediation of chromium contaminated soil: optimization of operating parameters under laboratory conditions. Journal of Hazardous Materials: 118 (1-3), 113-120 (2005).

Krishna, K.R. y Philip, L. Bioremediation of $\mathrm{Cr}(\mathrm{VI})$ in contaminated soils. Journal of Hazardous Materials: 121(1-3) 109-117 (2005).

Marsh, T.L. y M.J. McInerney, Relationship of hydrogen bioavailability to chromate reduction in aquifer sediments, Applied and Environmental Microbiology: 67, 1517-1521 (2001).

Morales-Barrera, L. y E. Cristiani-Urbina, Hexavalent Chromium Removal by a Trichoderma inhatum Fungal Strain Isolated from Tannery Effluent, Water Air Soil Pollution: 187, 327-336 (2008).

Muter, O., A. Patmalnieks, y A. Rapoport, Interrelations of the yeast Candida utilis: metal reduction and its distribution in the cell and medium, Process Biochemistry: 36, 963-970 (2001).

Palmer, C.H. y P.R. Wittbrodt, Processes affecting the remediation of chromium-contaminated sites, Environmental Health Perspect: 92, 25-40 (1991).

Pantaler, R.P. e I.V. Pulyaeva, A spectrophotometric study of complexation between chromium and chromazurol S. Journal of Analytical Chemistry: 40, 1634-1639 (1985).

Park, D., Y. Yun, J. Jo y J.M., Park, Mechanism of hexavalent chromium removal by dead fungal biomass of Aspergillus niger, Water Research: 39, 533-540 (2005).

Pas, M. y otros cuatro autores, Uptake of chromium (III) and chromium (VI) compounds in the yeast cell, Biometals: 5, 179-185 (2004).

Pepi, M. y F. Baldi, Modulation of chromium (VI) toxicity by organic and inorganic sulfur species in yeasts from industrial wastes, Biometals: 5, 179-185 (1992).

Prasenjit B. y S. Sumathi, Uptake of chromium by Aspergillus foetidus, Journal of Materials Cycles waste Management: 7, 88-92 (2005).

Ramírez-Ramírez, R. y otros seis autores, Cr(VI) reduction in a Chromate-resistant strain of Candida maltose isolated from the leather industry, Antonie van Leeuwenhoek: 85, 63-68 (2004).

Rodríguez, M.E., R.C. Miranda, R. Olivas y C.A. Sosa, Efectos de las condiciones de operación sobre la biosorción de $\mathrm{Pb}^{++} \mathrm{Cd}^{++}$and $\mathrm{Cr}^{+++}$, en solución por Saccharomyces cerevisiae residual, Información Tecnológica: 19, (6) 47-55 (2008).

Sandana Mala, J.G., B. Unni Nair, and R. Puvanakrishnan, Bioaccumulation and biosorption of chromium by Aspergillus niger MTCC 2594, Journal of General and Appliedd Microbiology: 52,179-186 (2006).

Seng, H. y Y.T. Wang, Biological reduction of chromium by E. coli, Journal of Environmental Engineering: 20, 560-572, (1994).

Smith, W.A., W.A. Apel, J.N. Petersen, y B.M. Peyton, Effect of carbon and energy source on bacterial chromate reduction, Bioremediation Journal: 6, 205-215 (2002).

Srivastava, S. y I.S. Thakur, Isolation and process parameter optimization of Aspergillus sp. for removal of chromium from tannery effluent, Bioresource Technology: 97, 1167-1173 (2006). 